\title{
Comparison of health-related quality of life between type 2 diabetic patients with and without locomotive syndrome
}

\author{
Rie Asakura ${ }^{1,2} \cdot$ Nobuyuki Miyatake ${ }^{2}$ Kazumi Dokai Mochimasu ${ }^{2}$. \\ Risa Kurato $^{2} \cdot$ Susumu Kuwana ${ }^{3}$
}

Received: 14 January 2016/Accepted: 26 April 2016/Published online: 4 May 2016

(c) The Japanese Society for Hygiene 2016

\begin{abstract}
Objective The aim of this study was to compare healthrelated quality of life (HRQOL) between type 2 diabetic patients with and without locomotive syndrome, which is a risk for becoming bedridden because of deteriorating locomotive organs.

Subjects and methods A total of 135 patients with type 2 diabetes mellitus ( $69.2 \pm 10.2$ years) were enrolled in this cross-sectional study. HRQOL was evaluated by the EuroQOL-5 (EQ-5D), and locomotive syndrome was evaluated by "loco-check," established the Japanese Orthopedic Association. Clinical data, such as anthropometric parameters, blood and urine examination results, blood pressure (BP), drug usage, and psychological distress, were analyzed.

Results Average $\mathrm{HbA1c}$ in all patients was $7.2 \pm 1.0 \%$, and 74 patients $(54.8 \%)$ were identified as having the locomotive syndrome. EQ-5D scores were significantly lower in type 2 diabetic patients with locomotive syndrome than in those without locomotive syndrome, even after adjusting for age, sex, body mass index (BMI), and HbAlc. By the multiple regression analysis, locomotive syndrome and age were identified as determinant factors of HRQOL in type 2 diabetic patients.

Conclusion In type 2 diabetic patients, lower HRQOL was a characteristic feature of subjects with locomotive
\end{abstract}

Rie Asakura

asakura1127@med.kagawa-u.ac.jp

Takamatsu City Office, Takamatsu 760-8571, Japan

2 Department of Hygiene, Faculty of Medicine, Kagawa University, Miki 761-0793, Japan

3 Kagawa Medical Office Attached To Takamatsu Municipal Hospital, Takamatsu 761-1703, Japan syndrome, even after adjusting for confounding factors. Prevention or management of locomotive syndrome may be beneficial for improving HRQOL in type 2 diabetic patients.

Keywords Locomotive syndrome - Loco-check - Type 2 diabetes mellitus · Health-related quality of life (HRQOL)

\section{Introduction}

Type 2 diabetes mellitus has become a public health challenge in Japan, as well as throughout the world. Approximately nine and a half million Japanese have type 2 diabetes mellitus, according to the Ministry of Health, Labour and Welfare of Japan [1]. Modern lifestyles, such as reduced physical activity and higher calorie diets, have been shown to be closely associated with the increase in type 2 diabetes mellitus. Furthermore, type 2 diabetes mellitus is associated with developing cerebrovascular disease and ischemic heart disease, reducing the healthrelated quality of life (HRQOL) [2, 3].

Locomotive syndrome, which has been shown to be a risk factor for becoming bedridden because of deteriorating locomotive organs, was defined by the Japanese Orthopedic Association [4]. In Japan, approximately $20 \%$ of individuals requiring "Long-Term Care" insurance were estimated to have the locomotive syndrome $[5,6]$. The final purpose of the therapy is increasing HRQOL in patients with type 2 diabetes mellitus [7]. In addition, it is well known that maintaining and increasing physical activity and performing exercise are milestone of the therapeutic strategy. Reducing locomotive organs may be closely associated with lower physical activity and exercise performance. Taken together, to increase HRQOL, prevention 
or improvement of locomotive syndrome is important for those with type 2 diabetes mellitus. Although the association between locomotive syndrome and HRQOL was evaluated in the general Japanese population by a crosssectional study [8], there have been no studies evaluating the link between HRQOL and locomotive syndrome in patients with type 2 diabetes mellitus.

Thus, we compared HRQOL in subjects with type 2 diabetes mellitus between those with and without locomotive syndrome in a cross-sectional study.

\section{Subjects and methods}

\section{Subjects}

A total of 135 type 2 diabetic patients, aged $69.2 \pm$ 10.2 years, were enrolled in this cross-sectional study after meeting the following criteria: (1) the subject was an outpatient at Kagawa Medical Office attached to the Takamatsu Municipal Hospital in Takamatsu, Japan, between August 4 and October 3, 2015; (2) the subject underwent the necessary examinations and completely answered the questionnaires; and (3) the subject provided written informed consent.

Approval was obtained from the Ethics Committee of Takamatsu Municipal Hospital, Takamatsu, Japan (20150727).

\section{Clinical parameters}

We evaluated age, sex, height $(\mathrm{cm})$, and body weight $(\mathrm{kg})$, levels of glutamic oxaloacetic transaminase (GOT), glutamic pyruvic transaminase (GPT), blood urea nitrogen (BUN), creatinine, triglyceride, HDL cholesterol, LDL cholesterol, blood sugar, and HbAlc, and urine sugar, as well as presence of proteinuria, hematuria, or microalbuminuria by the conventional laboratory methods. We also evaluated blood pressure (BP), drug usage, psychological distress, HRQOL, and locomotive syndrome. Psychological distress was measured by the K6 questionnaire [9-11], and HRQOL was evaluated by the Euro-QOL5 dimensions (EQ-5D), as previously described [12-16]. Locomotive syndrome was defined using the "loco-check," which was developed by the Japanese Orthopedic Association [17].

As described in a previous report [18], locomotive syndrome was defined as answering "yes" to any of the following questions: (1) You are unable to put on a pair of socks while standing on one leg; (2) You have stumbled or slipped in your house; (3) You need to use the handrail when going upstairs; (4) You are unable to cross the road at a crossing before the traffic light changes; (5) You have difficulty walking continuously for $15 \mathrm{~min}$; (6) You find it difficult to walk home carrying a shopping bag weighing approximately $2 \mathrm{~kg}$ (e.g., two 1-L cartons of milk); and (7) You find it difficult to do housework requiring physical strength, such as using a vacuum cleaner, moving futons (traditional Japanese bedding) in and out of the closet.

\section{Statistical analysis}

Data were expressed as mean $\pm \mathrm{SD}$. The unpaired $t$-test was used to compare the clinical parameters of the type 2 diabetes mellitus subjects between those with and without locomotive syndrome. Analysis of covariance (ANCOVA) was used to adjust for confounding factors, where $p<0.05$ was considered significant. Multiple regression analysis was then performed to evaluate which factors were determinant for HRQOL in type 2 diabetic patients. All statistical analyses were performed with the IBM SPSS Statistics 22 software (IBM Japan, Tokyo, Japan).

\section{Results}

The clinical profile of the enrolled type 2 diabetes mellitus subjects are summarized in Table 1. Mean age was $69.2 \pm 10.2$ years and HbA1c was $7.2 \pm 1.0 \%$. Seventyfour subjects had locomotive syndrome (54.8\%), with a mean EQ-5D score of $0.768 \pm 0.191$.

Table 2 shows the comparison of clinical parameters between type 2 diabetic patients with and without locomotive syndrome. Age, BMI, and K6 scores in subjects with locomotive syndrome were significantly higher, and height and EQ-5D were significantly lower than in subjects without locomotive syndrome. After adjusting for age and sex, body weight, BMI, and K6 scores in patients with locomotive syndrome were significantly higher, and EQ-5D scores were significantly lower than in those without locomotive syndrome. After further adjustment for age, sex, BMI, and HbA1c, only EQ-5D scores in patients with locomotive syndrome were significantly lower than in those without locomotive syndrome. There were no other significant differences in clinical parameters between those with and without locomotive syndrome.

Finally, we investigated what factors affect EQ-5D score in patients with type 2 diabetes mellitus (Table 3 ). By the multiple regression analysis, we used EQ-5D score, as a dependent variable; and locomotive syndrome, age, sex, $\mathrm{BMI}$, and $\mathrm{HbA} 1 \mathrm{c}$, as independent variables. Locomotive syndrome $(\beta: 0.387, p<0.001)$ and age $(\beta:-0.192$, $p=0.023$ ) were identified as determinant factors of EQ$5 \mathrm{D}$ score in patients with type 2 diabetes mellitus. 


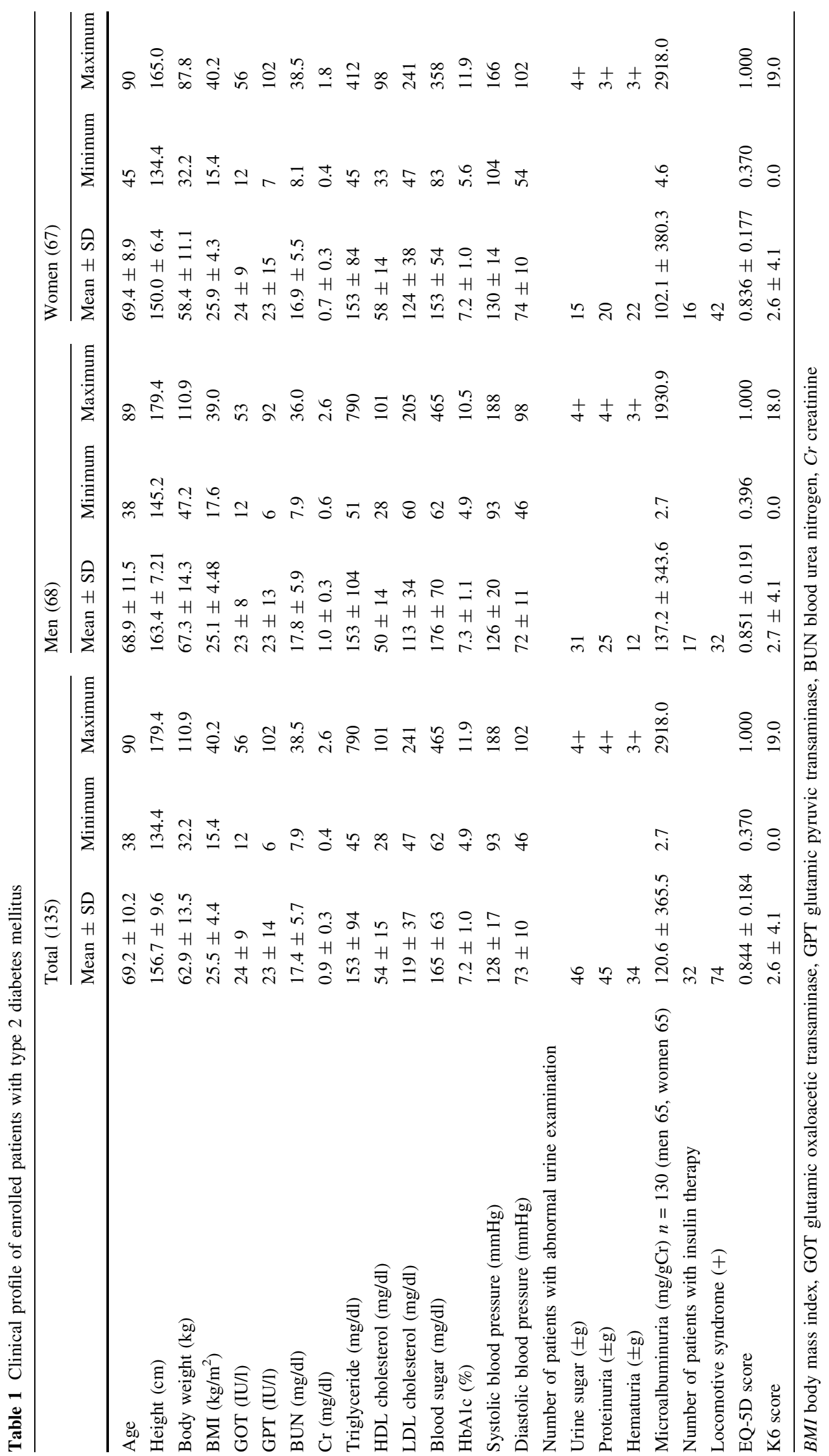


Table 2 Comparison of clinical parameters between type 2 diabetic patients with and without locomotive syndrome

\begin{tabular}{|c|c|c|c|c|c|}
\hline & \multirow{2}{*}{$\begin{array}{l}\text { Locomotive syndrome }(+) \\
\text { Mean } \pm \text { SD }\end{array}$} & \multicolumn{4}{|c|}{ Locomotive syndrome $(-)$} \\
\hline & & Mean \pm SD & $p$ & $p^{1}$ & $p^{2}$ \\
\hline Number of subjects & $n=74(54.8 \%)$ & $n=61(45.2 \%)$ & & & \\
\hline Age & $71.4 \pm 10.9$ & $66.5 \pm 8.8$ & 0.006 & & \\
\hline Height $(\mathrm{cm})$ & $154.9 \pm 9.5$ & $159.0 \pm 9.2$ & 0.012 & 0.758 & 0.838 \\
\hline Body weight (kg) & $64.1 \pm 14.6$ & $61.4 \pm 12.0$ & 0.251 & $<\mathbf{0 . 0 0 1}$ & 0.818 \\
\hline BMI $\left(\mathrm{kg} / \mathrm{m}^{2}\right)$ & $26.5 \pm 4.5$ & $24.2 \pm 3.8$ & 0.002 & $<\mathbf{0 . 0 0 1}$ & \\
\hline GPT (IU/l) & $23 \pm 16$ & $23 \pm 10$ & 0.852 & 0.186 & 0.985 \\
\hline BUN(mg/dl) & $17.8 \pm 5.9$ & $16.8 \pm 5.4$ & 0.315 & 0.701 & 0.556 \\
\hline $\mathrm{Cr}(\mathrm{mg} / \mathrm{dl})$ & $0.9 \pm 0.3$ & $0.9 \pm 0.4$ & 0.872 & 0.913 & 0.742 \\
\hline Triglyceride (mg/dl) & $147 \pm 82$ & $160 \pm 107$ & 0.438 & 0.561 & 0.195 \\
\hline HDL cholesterol (mg/dl) & $54 \pm 15$ & $54 \pm 15$ & 0.939 & 0.572 & 0.535 \\
\hline LDL cholesterol (mg/dl) & $118 \pm 40$ & $119 \pm 33$ & 0.908 & 0.832 & 0.975 \\
\hline Blood sugar (mg/dl) & $160 \pm 60$ & $171 \pm 66$ & 0.322 & 0.510 & 0.346 \\
\hline $\mathrm{HbA} 1 \mathrm{c}(\%)$ & $7.3 \pm 1.1$ & $7.2 \pm 0.9$ & 0.578 & 0.637 & \\
\hline Systolic blood pressure $(\mathrm{mmHg})$ & $128 \pm 15$ & $128 \pm 20$ & 0.849 & 0.833 & 1.000 \\
\hline Diastolic blood pressure (mmHg) & $73 \pm 10$ & $73 \pm 11$ & 0.711 & 0.421 & 0.996 \\
\hline EQ-5D score & $0.768 \pm 0.191$ & $0.936 \pm 0.123$ & $<0.001$ & $<\mathbf{0 . 0 0 1}$ & $<\mathbf{0 . 0 0 1}$ \\
\hline K6 score & $3.4 \pm 4.4$ & $1.7 \pm 3.5$ & 0.016 & 0.031 & 0.097 \\
\hline
\end{tabular}

Bold indicates $P<0.05$

$\mathrm{P}^{1}$ Adjusting for age and sex, $\mathrm{P}^{2}$ Adjusting for age, sex, BMI and HbA1c, BMI body mass index, GPT glutamic pyruvic transaminase, BUN blood urea nitrogen, $\mathrm{Cr}$ creatinine

Table 3 Multiple regression analysis between EQ-5D scores and clinical parameters

\begin{tabular}{llr}
\hline Dependent variables: EQ-5D scores & $\beta$ & \multicolumn{1}{l}{$p$} \\
\hline Independent variables & & \\
Locomotive syndrome & 0.387 & $\mathbf{< 0 . 0 0 1}$ \\
Age & -0.192 & $\mathbf{0 . 0 2 3}$ \\
Sex & 0.031 & 0.688 \\
BMI & -0.096 & 0.257 \\
HbA1c & -0.070 & 0.366 \\
\hline
\end{tabular}

Bold indicates $P<0.05$

$B M I$ body mass index

$R^{2}=0.248, p<0.05$

\section{Discussion}

In the present study, we evaluated the prevalence of locomotive syndrome in patients with type 2 diabetes mellitus. EQ-5D scores in patients with locomotive syndrome were significantly lower than in those without locomotive syndrome.

Using "loco-check," Iizuka et al. reported that $39.6 \%$ of subjects from the general population had locomotive syndrome (66.1 \pm 10.9 years), which is supported by our results [8]. Hirano et al. also reported that 62 subjects (16.1\%) among 386 community-dwelling subjects over the age of 50 had locomotive syndrome [19]. In the present study, we evaluated the prevalence of locomotive syndrome in patients with type 2 diabetes mellitus, and found that the prevalence of locomotive syndrome was higher than that of the general Japanese population [8, 19]. Although the present results were obtained in only one local clinic in Kagawa Prefecture, Japan, these results may provide useful data on the prevalence of locomotive syndrome in patients with type 2 diabetes mellitus.

According to the factors associated with HRQOL in patients diabetes mellitus, Saleh et al. found that age, female gender, income, education, family history, and duration of diabetes mellitus were important factors for HRQOL using EQ-5D in 500 type 2 diabetic patients in a cross-sectional study [20]. Porojan et al. also showed that the prevention of complications and control of blood sugar were important for HRQOL evaluated using Medical Outcomes Study 36-Item Short-Form Health Survey (SF36) [21]. In addition, assessment of patients with type 2 diabetes mellitus using SF-36 identified exercise and training, particularly aerobic exercise, as factors that may improve HRQOL [22]. In the present study, it is noteworthy that presence of locomotive syndrome, rather than age, sex, BMI, or HbAlc, was most associated with HRQOL in patients with type 2 diabetes mellitus.

In turn, there are some reports of the relationship between locomotive syndrome and HRQOL. Ebihara et al. showed 
that the HRQOL using EQ-5D in subjects with locomotive syndrome was significantly lower than in those without locomotive syndrome in community-dwelling people [23]. In outpatients of orthopedic hospitals and/or clinics, HRQOL by SF-36, grip strength, level of physical activity in daily life, and psychological state were significantly lower in subjects with locomotive syndrome than in those without locomotive syndrome [24]. To the best of our knowledge, this is the first investigation of HRQOL and locomotive syndrome in type 2 diabetic mellitus subjects, and we observed a significant difference in EQ-5D score between those with and without locomotive syndrome. This difference was still observed after adjusting for age, sex, BMI, and $\mathrm{HbAlc}$. In addition, the multiple regression analysis showed that the presence of locomotive syndrome was associated with HRQOL in patients with type 2 diabetes mellitus. Taken together, physical activity and performing exercise may be difficult in type 2 diabetic patients with locomotive syndrome, leading to increased time of being bedridden. Therefore, prevention or management of locomotive syndrome using "loco-check" is recommended for improving HRQOL in patients with type 2 diabetes mellitus.

There are some potential limitations to the present study. First, the study was of a cross-sectional, not longitudinal, design. Second, the type 2 diabetes mellitus patients enrolled in this study were outpatients at only one clinic in Takamatsu city, Japan. Third, the factors underlying the association between locomotive syndrome and lower EQ$5 \mathrm{D}$ score remain to be clarified. Although the diabetic complications, such as retinopathy, nephropathy, and cardiovascular diseases, might be associated with HRQOL, we could not accurately evaluate the state and the influence of complications. Fourth, EQ-5D questionnaires include the items of physical activity and the utility scores were calculated. Therefore, HRQOL evaluated by other methods would be needed to confirm the relation between HRQOL and locomotive syndrome. Nevertheless, prevention or management of locomotive syndrome in type 2 diabetic patients may increase HRQOL. Thus, further investigations are required to further clarify such a link.

\section{Compliance with ethical standards}

Conflict of interest The authors declare that there were no conflicts of interest in this study.

\section{References}

1. http://www.mhlw.go.jp/stf/houdou/0000032074.html (2015.12.01) (in Japanese). Ministry of Health, Labor and Welfare:National health and nutrition examination Survey 2012.

2. Goto A, Noda M, Matsushita Y, Goto M, Kato M, Isogawa A, et al. Hemoglobin a1c levels and the risk of cardiovascular disease in people without known diabetes: a population-based cohort study in Japan. Medicine (Baltimore). 2015;94:e785.

3. Sakamaki H, Ikeda S, Ikegami N, Uchigata Y, Iwamoto Y, Origasa $\mathrm{H}$, et al. Measurement of HRQL using EQ-5D in patients with type 2 diabetes mellitus in Japan. Val Health. 2006;9(1):47-53.

4. Nakamura KA. "Super-aged" society and the "locomotive syndrome". J Orthop Sci. 2008;13:1-2.

5. http://www.mhlw.go.jp/toukei/list/20-19-1.html (2015.12.01) (in Japanese). Ministry of Health, Labor and Welfare:Comprehensive Survey of Living Conditions 2007.

6. Nakamura K. The concept and treatment of locomotive syndrome: its acceptance and spread in Japan. J Orthop Sci. 2011;16:489-91.

7. Eiichi A, Nobuya I, Toyoshi I, Kazunori U, Yukio T, Jirou N, et al.Treatment Guide for Diabetes 2014-2015, Edited by Japan Diabetes Society. Bunkodo; 2014. p 24 (in Japanese).

8. Iizuka Y, Iizuka H, Mieda T, Tajika T, Yamamoto A, Takagishi K. Association between "loco-check" and EuroQol, a comprehensive instrument for assessing health-related quality of life:a study of the Japanese general population. J Orthop Sci. 2014;19:786-91.

9. Kessler RC, Andrews G, Colpe LJ, Hiripi E, Mroczek DK, Normand SL, et al. Short screening scales to monitor population prevalences and trends in non-specific psychological distress. Psychol Med. 2002;32:959-76.

10. Furukawa TA, Kessler RC, Slade T, Andrews G. The performance of the K6 and K10 screening scales for psychological distress in the Australian National Survey of Mental Health and Well-Bing. Psychol Med. 2003;33:357-62.

11. Kessler RC, Barker PR, Colpe LJ, Epstein JF, Gfroerer JC, Hiripi E, et al. Screening for serious mental illness in the general population. Arch Gen Psychiatry. 2003;60:184-9.

12. EuroQol Group. EuroQol; a new facility for the measurement of health-related quality of life. Health Policy. 1990;16:199-208.

13. Rabin R, de Charro F. EQ-5D: a measurement of health status from the EuroQol Group. Ann Med. 2001;33:337-43.

14. Brooks R. EuroQol: the current state of play. Health Policy. 1996;37:53-72.

15. Ikeda S, Ikegami N. Health status in Japanese population: results from Japanese EuroQol study. J Health Care Soc. 1999;9:83-92.

16. Ikegami N, Fukuhara S, Ikeda S.QOL evaluation handbook for clinical diagnosis. Igaku Shoin; 2001. p 45-9 (in Japanese).

17. https://locomo-joa.jp/locomo/ (2015.12.01) (in Japanese).

18. https://locomo-joa.jp/check/lococheck/ (2015.12.01) (in Japanese).

19. Hirano K, Imagawa S, Hasegawa Y, Ito Z, Muramoto A, Ishiguro $\mathrm{N}$. The influence of locomotive syndrome on health-related quality of life in a community-living population. Mod Rheumatol. 2013;23:939-44.

20. Saleh F, Ara F, Mumu SJ, Hafez MA. Assessment of healthrelated quality of life Bangladeshi patients with type 2 diabetes using the EQ-5D: a cross-sectional study. BMC Res Notes. 2015;8:497.

21. Porojan M, Poanta L, Dumitrascu DL. Assessing health related quality of life in diabetic patients. Rom J Intern Med. 2012;50:27-31.

22. Myers VH, Kramer K, McVay MA, Harris MN, Brashear MM, Johnson WD, et al. Exercise training and quality of life in individuals with type 2 diabetes: a randomized controlled trial. Diabetes Care. 2013;36:1884-90.

23. Ebihara C, Arai T, Fujita H, Katou G, Sinooka S, Morita Y, et al. The relationship between locomotive syndrome and quality of life of community-dwelling elderly people. Rigakuryoho Kagaku. 2013;28:569-72 (in Japanese).

24. Nakagoshi R, Takemasa S, Nakayama H, Mori Y. The relationship between locomotive syndrome and daily activity and healthrelated quality of life of the community-dwelling elderly. Rigakuryoho Kagaku. 2015;30:557-61. 